International Egyptian Journal of Nursing Sciences and Research (IEJNSR)

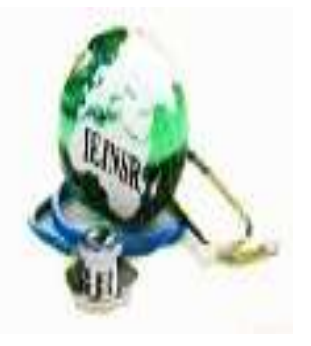

Review article

Received 2021-06-7

Accepted 2021-06-13

Published 1-7-2021

\title{
Bedside Clinical handover in health care organization
}

\author{
Nagwa Gouda Ahmed Abd-Elmoghith \\ Assistant Professor of Nursing administration, Faculty of Nursing, Kafrelsheikh University
}

Corresponding author: nagwa_ahmed@nur.kfs.edu.eg

\begin{abstract}
Ineffective communication is now widely acknowledged as a factor in hospital patient harm. Clinical handover has been identified as a crucial place for communication issues, according to study. In addition to structural changes, there has been a broader emphasis on involving the patient and their caregivers in the handover process. Patient-centered care models are widely promoted in healthcare recommendations, especially in handover. Patient involvement in handover is one facet of patient-centered care, in which patients are treated as partners in their treatment. Nurses can adjust their clinical handovers to reflect patients' opinions, views and encourage their active participation in decision-making by first understanding the patient perspective. This article reviews the bedside clinical handover in nursing clinical practice.
\end{abstract}

\section{Keywords: clinical handover, patient centered care, and health care}

\section{INTRODUCTION}

Every day, in a multitude of ways, in all health care environments, clinical handover is performed. Patients can be extremely badly impacted by bad or absent clinical handover or failure to pass knowledge, transparency, and accountability. cross all disciplines, existing handover procedures are extremely complex and inconsistent. This may contribute to inconsistencies in the content and reliability of data supplied. In addition, Clinical handover can define as shift of professional responsibility and accountability to another individual / family / primary caregiver or profession on 
a temporary or permanent basis for any or all aspects of treatment for a patient or client $(\mathbf{1}, \mathbf{2}, \mathbf{3})$. The four basic kinds of handover, according to Miller (4), are recorded, bedside, written, and verbal (traditional). The necessity for regular assessments of the handover process, written guidelines for handover content, and the usage of a pre-prepared handover sheet were all given as suggestions for improvement.

The handover process was often fragmented and was reduced in time and importance by various factors, including interruption and competing demands. information tended to be delivered as numbers, abbreviations, and acronyms, which was detrimental to patient care. Meanwhile, incident reporting, complaints and staff grievances had become repetitive. sometimes, relevant clinical information was not passed to the next shift and sometimes irrelevant information was discussed. Other problems with clinical handovers included their location at a staff station away from the patients and, for patients and their families, a lack of information on and involvement in organization processes and care plans ${ }^{(5)}$.

, the United Nations has stigmatized all forms of the practice, and rejecting the medicalization of the practice. ${ }^{(4)}$

\section{Clinical handover center patient care}

To increase the accuracy and timeliness of knowledge transmission, clinical handover was created by providing patient feedback and adding the variety of communication information that can be collected at the point of care ${ }^{(6,7)}$.

The healthcare provider is associated with patients in this way as a reflexive, vital listener to develop a trustworthy relationship. Patient-centered treatment is also patient-empowering, with patients deciding, according to their expertise, skills, desires and privileges, the degree of their participation in care ${ }^{(\mathbf{8})}$.

\section{Clinical handover occurs between:}

- Staff nurse during three times a day "morning, afternoon, and night shifts" the nurse will be introduced herself to the next shift and discussed plan of care, review bedside notes, medication charts and any invasive connections about the patients they have, any confidential aspects of care or any urgent or nonurgent needs can discussed with the nurse after handover completed ${ }^{(9)}$.

A clinical handover nurses requires ${ }^{(10)}$ :

- Communicate effectively and appropriately with other health care provider.

- Using appropriate terminology with completely understand.

- Analysis the documentation charts

- Focus on patient observation and clinical skills.

Five tips to polish your handover technique $^{(11)}$ :

1. Be organized: when handing over try to follow logical sequence include clinical observations, diagnostic findings, and procedures. Remember to mention any allergies, as well as significant patient history and other medical issues.

2. Stay focused: when handing over keep focus on knowing what is important occurred during your shift. Reiterate the patient's present status and nursing care plan - and then continue.

3. Communicate clearly: be concise and talk clearly, avoid abbreviation. Make use of medical and nursing jargon. Avoid using acronyms or being vague. Explain any irregularities in a patient's care or therapies that a new graduate or junior member of staff might be unfamiliar with if you are passing over to them. Check to see if your colleague is paying attention and 
listening - if they are, ask if they are distracted.

4. Be patient centered: focus on patient general condition not only clinical condition. What has your patient's mood been like? It is not only about the clinical information. Are they unhappy, anxious, worried, or tearful? Any special concerns or wants of your patient should be communicated. If you get a feeling something is not quite right but your patient is clinically stable, let your nurse know trust and share your sixth sense.

5. Allow time: make the most of your hand over time. While clinical handover is a key part of successful time management, it is also crucial that all pertinent information be relayed. When giving a taped handover report, try not to rush or speak too quickly. If it is a verbal handover, be open and welcome inquiries. If a coworker does not seem to understand what you are saying, repeat or explain it.

\section{Management responsibilities ${ }^{(12)}$ :}

The nurse manager's has responsibility with the clinical handover to ensure the following principles are applied:

- While handover is taking place, continues patient care as required.

- The location, start times, and duration of the handover are all determined.

- The time available and clinical demands of the shift are reflected in group handover.

- The structure and expectations of handover are well understood among nurses.

- Disruptions are kept to a minimum.

- Handover is attended by all required nurses.

- The handover format is used to organize communication.

- Patients are assigned to nurses who are qualified to care for them.
- Handover process audits are done as needed.

- In all continuous process operations, particularly in the health care sector, preserving continuity between work shifts is critical. It is especially important when considering the long-term care that a hospitalized patient need, which goes beyond a single doctor or team. In a 24-hour work environment, a shift handover mechanism is required to allow personnel changes with minimal disturbance to the functioning of a ward or unit. The purpose of handover is to ensure that taskspecific patient information is communicated accurately and reliably across shift changes, resulting in a relatively safe and successful continuous work environment ${ }^{(13)}$.

- Conclusion:

- Patients can participate as active participants in their own care through clinical handover. In addition, the handover allowed for more patient-centered care and consideration. In fact, Miscommunication-related medical problems have also been linked to health workers' varying levels of participation with clinical handover and communication styles. To address these issues, consistent operational norms for handovers are required.

\section{REFERENCES}

1. Australian Commission on Safety and Quality in Health Care (2010). OSSIE Guide to 
Clinical Handover Improvement. Sydney. ACSQHC, 2010.

2. Australian Commission on Safety and Quality in Health Care (2012). Safety and Quality Improvement Guide Standard 6: Clinical Handover (October 2012). Sydney. ACSQHC, 2012. Sydney. Commonwealth of Australia

3. ACSQHC, 2019. (Accessed 16 May 2019) sited

in: https://nationalstandards.saf etyandquality.gov.au/topic/user-

guide-acute-and-community-

health-service-organisations-

provide-care

children/communicating

4. Miller C. (1998). Ensuring continuing care: styles and efficiency of the handover process. Aust J Adv Nurs 16: 23-7

5. Wilson, R. (2011). Improving clinical handover in emergency departments. J Emergency nurse 19(1): 22-26. Doi: 10.7748/en2011.04.19.1.22.c8446

6. Broekhuis, M., \& Veldkamp, C. (2007). The usefulness and feasibility of a reflexivity method to improve clinical handover. Journal of Evaluation in Clinical Practice, 13, 109- 115.

7. Cahill, J. (1998). Patient's perceptions of bedside handovers. Journal of Clinical Nursing, 7, 351359.

8. Brown, D., McWilliam, C., \& Ward-Griffin, C. (2006). Clientcentred empowering partnering in nursing. Journal of Advanced Nursing, 53 (2), 160-168.

9. The Government of Western Australia East Metropolitan Health Service (2020) https://www.ahs.health.wa.gov.au/ For-patients-and-visitors/Yourhospital-stay/Clinical-handover

10. Flinders University (2020). Clinical communication patient handover. https://nursing.flinders.edu.au/stud ents/studyaids/clinicalcommunicati on/page.php?id=11

11. Australia Nursing \& Midwifery Journal (2020). 5 tips to a good clinical handover https://anmj.org.au/5-tips-to-agood-clinical-handover/

12. Mardis T, Mardis M, Davis J, Justice EM, Holdinsky SR, Donnelly J, RagozineBush H, Riesenberg LA. (2016). Bedside Shift-to-Shift Handover. Journal of Nursing Care Quality 31(1):54-60

13. Kerr MP. (2002). A qualitative study of shift handover practice and function from a socio-technic 